\title{
RARE CARDIAC ANEURYSM IN A YOUNG ADULT
}

\author{
BY \\ KEVIN P. CLEARKIN AND HENRY BUNJE \\ From the Departments of Pathology and Medicine, University College of the West Indies, Mona, \\ St. Andrew, Jamaica
}

(RECEIVED FOR PUBLICATION OCTOBER 4, 1954)

About $85 \%$ of cardiac aneurysms are caused by coronary occlusion (Sternberg, 1914). The remainder have been described following trauma (French, 1912), lead poisoning (Carstens, 1950), pyaemia (Wilson, 1926), tuberculosis (Jones and Tilden, 1942), rheumatic carditis (Parkinson, Bedford, and Thomson, 1938), syphilitic myocarditis (Aronstein and Neuman, 1941), interstitial myocarditis (Beaudet and Boermans, 1947), and congenital defects.

Aneurysms arising from congenital anomalies of the left ventricle, apart from those in the interventricular septum, are extremely rare; in fact we have been able to find only one case described in the literature where an aneurysm arose from a primary defect in the development of the muscle bundles in the left ventricle (Ungerleider and Gubner, 1945).

Burn, Hollander, and Crawford (1943) encountered a large semiloculated aneurysm arising from the fibrous band of the mitral ring in a 13year-old girl. They claimed that the anatomical arrangement of the structure was suggestive of a congenital abnormality, but their finding of typical Aschoff bodies throughout the myocardium throws doubt on this, and an inflammatory cause seems more likely. The same authors, after an intensive search through the literature, could find only three reports of aneurysms similar to theirs (Hunter and Benson, 1933 ; Corvisart, 1812 ; Berlin and Hallén, 1938).

Bland, White, and Garland (1933) listed eight cases of ventricular aneurysm in children in whom the left coronary artery arose from the pulmonary artery. They added one of their own. It was suggested that in these cases the left ventricle had an inadequate blood supply because of the relatively low pressure in the pulmonary artery.

We present here a case of ventricular aneurysm, which we believe to be congenital in origin, in a 22-year-old man.

\section{CASE RePort}

The patient, a Negro, was admitted to the University College Hospital in Jamaica on June 15, 1953. Two years previously he had had a radiograph of the chest in the B.C.G. vaccination scheme in Kingston, and was then told that he had "a lump in his chest" which he believed was in front. He had no further radiographs until he came to hospital this time. For two years he had had a cough which gradually got worse and was productive of a whitish sputum or mucus in fair quantity. He had never coughed blood. During the six months before admission he had had "colds" during which the cough increased. In the same period he had abdominal and back pains, and pains in the side of the chest ; and in the latter three months, listlessness, fatigue, nausea with flatulence, and sweating about the head at nights. Four days before admission he awoke with a sudden pain in the right side of the chest and under the right ribs, which was aggravated by coughing and was severe enough to prevent him from walking. For these four days his appetite was poor. He thought he had lost about $7 \mathrm{lb}$. in weight. There had been no urinary symptoms and the bowels had been open regularly. There were no known contacts with persons having chest symptoms. About a year before admission he had "squeezed himself on a bicycle," and had to have an orchidectomy, for which he was in hospital for six weeks and unable to work afterwards for four to five months.

On examination the mucous membranes were pale. $\mathrm{He}$ was dyspnoeic and orthopnoeic, blood pressure $100 / 80 \mathrm{~mm}$. $\mathrm{Hg}$; temperature $102^{\circ}$; pulse 134 , respirations 40 . The temperature, pulse, and respirations continued at these levels throughout his three weeks in hospital. For the most part the temperature was remittent and for his second week in hospital intermittent. The cardiac impulse was diffuse and the apex beat difficult to define. It apparently varied between a normal position in the fifth space in the nipple line and the sixth space in the anterior axillary line. The heart sounds were, on the whole, normal, except that at the pulmonary base the sounds were louder than at the aortic base and the pulmonary second sound slightly increased. There was very little movement with respiration and no difference between the movements of the two sides. Resonance on percussion was 
grossly impaired in the middle and lower zones in front and grossly impaired in the middle and lower zones behind, but much more so on the right. At the upper level of the impaired resonance on the right in front and laterally there was bronchial breathing. This was also heard posteriorly but very faintly. Breath sounds in the right lower zone were poor but nevertheless present. They were louder in the left lower zone. There were a few moist sounds in the same regions. There was tenderness in the epigastrium, and the liver edge was felt between two and three fingerbreadths below the costal margin.

On June 16 the haemoglobin was 10.7 g. \%, R.B.C. 4.2 m. $/$ c.mm., P.C.V. $38 \%$, M.C.V. 92 c. $\mu$, E.S.R. $23 \mathrm{~mm}$. in one hour (Wintrobe), W.B.C. 7,950/c.mm. ; serum tests for syphilis were positive at 1 in 4 dilutions. Postero-anterior and lateral chest radiographs showed a large rounded mass anteriorly in the lower thorax. Both lower zones of the lung fields were obscured by dense shadows. Fluoroscopy revealed a large liquid effusion in the right pleural cavity and a well-defined, rounded mass on the left side continuous with the heart. The left diaphragm was low, but showed normal movement. The right diaphragm could not be seen. A barium swallow was normal. Two specimens of sputum were negative for tubercle bacilli on direct smear and on culture, and the pleural fluid was always sterile on culture. Aspiration of fluid from the right chest produced $500 \mathrm{ml}$. of blood-tinged yellow liquid which clotted on standing. The patient felt some relief after this. The liquid had a total protein content of $4.5 \mathrm{~g} . \%$ (albumin $2.8 \mathrm{~g} . \%$ and globulin 1.7 g.\%). Approximately 10 lymphocytes and 20 red blood cells were seen per high-power field. After this first aspiration, further removal of fluid from the right chest over the next two weeks produced in all $4,000 \mathrm{ml}$., without much relief of the respiratory distress. Aspiration of the left side was attempted at various sites in the lower antero-lateral region. Only $20 \mathrm{ml}$., of a fluid similar to that on the right, was obtained. Once the needle was in contact with the heart or a tumour connected with it and a small amount of viscous blood was aspirated.

As a last resort an exploratory thoracotomy was decided upon, as the patient's condition was gradually deteriorating. This was attempted on the twentysecond day after admission, but the patient died under anaesthesia before the surgeon began.

The post-mortem examination was carried out 24 hours after death. The subject was a young adult Negro of rather light build (body weight $128 \mathrm{lb}$., length $165 \mathrm{~cm}$.). The fingers and toes were slightly clubbed.

The right pleural cavity contained dense adhesions, and scattered over both pleural surfaces were numerous miliary tubercles. There was a small blood-stained effusion. The left pleural cavity contained a small serous effusion, but otherwise there was no abnormality. In the abdomen the peritoneal surface was smooth and glistening. The pericardial cavity was obliterated by dense fibrous adhesions, but there was no evidence of tuberculosis there.
The mediastinal and mesenteric lymph nodes were enlarged and contained caseating foci. One such node was attached to the parietal pericardium.

On sectioning the right lung a primary tuberculous focus, $\frac{3}{4} \mathrm{~cm}$. in diameter, was found in the lower lobe. It lay immediately above the diaphragmatic surface. No tubercles were visible in the lung parenchyma.

The great vessels showed no congenital abnormality except perhaps the aorta, which had a mean circumference of $43 \mathrm{~cm}$. compared with the normal of $52.34 \mathrm{~cm}$. (Millar and Ross, 1942). The heart weighed $890 \mathrm{~g}$. From the anterior and lateral surfaces of the left ventricle there arose a saccular, lobulated, aneurysmal swelling measuring $11.5 \times 11 \times 7 \mathrm{~cm}$. and situated $2.3 \mathrm{~cm}$. and $2.5 \mathrm{~cm}$. from the mitral valve and apex respectively. Medially it extended as far as the interventricular septum. The right ventricle was dilated and its wall was $0.5 \mathrm{~cm}$. thick. On sectioning the aneurysm it was found to be multilocular and filled with blood clot, the greater part of which appeared to be fairly fresh. The average thickness of the wall was $0.2 \mathrm{~cm}$., and did not appear to contain any muscle. Three main compartments, one large and two smaller ones, measured respectively $11 \times$ $7 \times 9 \mathrm{~cm}$., $4 \times 2 \frac{1}{2} \times 3 \mathrm{~cm}$., and $3 \times 4 \times 3 \mathrm{~cm}$. The largest lay in the most anterior position and communicated directly with the left ventricle through a large oval orifice, $4 \mathrm{~cm}$. in its greatest diameter. Posterior to this was another smaller opening which opened into the smallest loculus. This in turn communicated with the other two through defects in their septal walls. Most of the surfaces were covered by organizing thrombus, but those that were not were smooth and glistening. The aneurysms were anterior and lateral to the anterior papillary musçle (Fig. 1).

The heart valves were thin and membranous. The chordae tendineae showed no thickening. The myocardium was of normal consistency and colour. The

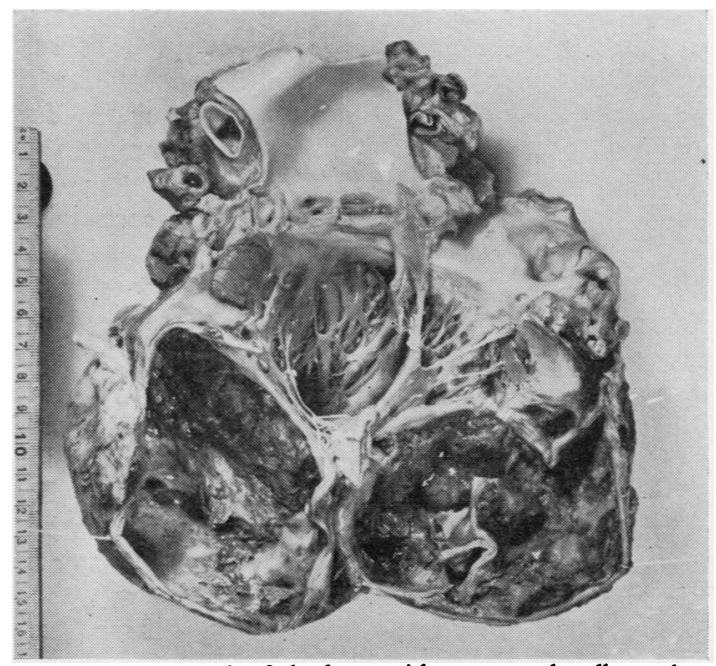

Fig. 1.-Photograph of the heart with aneurysmal walls partly cut away. 
coronary ostia were normally situated and were not narrowed, and the coronary arteries were normally distributed and showed no thickening or any occlusions.

Examination of the lungs, liver, and spleen showed terminal congestive changes. Study of the other organs, including the brain, yielded no relevant data.

Histological examination of a number of sections of the aneurysm showed a compact hyalinized fibrous tissue wall with no endothelial lining. In many areas active organization of blood clot was in progress. The outer part of the wall was composed of vascular connective tissue in which there were groups of fibroblasts. The vessels appeared engorged, with a moderate degree of perivascular cuffing by plasma cells and lymphocytes. The myocardium close to the aneurysm showed a diffuse fibrosis, but this was not apparent in sections taken well away from the lesion or in any sections from the right ventricle. The mitral valve cusps showed no thickening, vascularization, or cellular infiltration. Cellular reaction was absent in the interstitial tissue of the myocardium, and there was no sign of obliterative endarteritis of the smaller vessels.

Examination of tissue from the right pleural cavity and mediastinal lymph nodes showed typical tuberculous caseation with numerous tubercles. Multiple sections of the parietal pericardium showed no evidence of any tuberculous involvement.

\section{Discussion}

Despite the positive reaction for syphilis (1 in 4 dilutions) in this patient, it must be extremely rare, if at all possible, to get a syphilitic primary myocarditis leading to the formation of an aneurysm, especially at this age. In no organ was there gross or histological evidence of syphilis. Gore (1947) concluded that, except for a rare gumma, myocardial changes in syphilis are almost entirely caused by vascular changes, i.e., narrowing of the coronary ostia. Gould (1953) doubted if it occurred at all. Also, as yaws is common in Jamaica, it is more than likely that this was responsible for the weakly positive serological findings.

Joachim and Mays (1927) published a case report of a man aged 25 who died suddenly. Necropsy revealed a large left ventricular aneurysm and an occlusion of the anterior descending coronary artery near its origin. The patient had suffered a severe chest injury at the age of 12 years. Higginson and Keeley (1951) described a cardiac aneurysm in a 19-year-old Bantu woman who had tuberculosis of the hilar lymph nodes and spleen. The heart and pericardium were free from tuberculosis. This description, however, differs from ours in that the aneurysm had evolved from the mitral valve ring and the smaller arteries showed an obliterative endarteritis which they presumed was the basic pathological process.

Vivas-Salas (1948) reported a case of a ventricular aneurysm in a 7-year-old child, but this was diagnosed on radiological evidence and was probably due to an anomalous origin of the coronary artery from the pulmonary artery.

In our case no history of trauma was obtainable nor was there any thickening or occlusion of the coronary vessels. Histological examination of the myocardium failed to reveal any evidence of interstitial myocarditis or rheumatic disease. Although the right pleura and mediastinal lymph nodes showed active tuberculosis, the heart and pericardium were completely free of it. The aneurysm appeared to have been due to a congenital defect, a primary abnormality in the development of the muscles bundles of the left ventricle.

The only other similar case we have been able to find in the literature was that described by Ungerleider and Gubner (1945), and the details are extremely meagre. They showed the radiographic configuration of a ventricular aneurysm in a 15year-old girl confirmed by post-mortem examination (no details given) and added that it was due presumably to an anomaly in the development of muscle bundles.

Our thanks are due to Dr. Philip Hugh-Jones, physician in charge of the case, and to Dr. G. Bras for the photograph.

\section{REFERENCES}

Aronstein, C. G., and Neuman, L. (1941). Amer. J. clin. Path., 11, 128.

Beaudet, S. C., and Boermans, C. (1947). Rev. méd. Liège, 2, 621.

Berlin, R., and Hallén, L. (1938). Acta med. scand., 95, 34.

Bland, E. F., White, P. D., and Garland, J. (1933). Amer. Heart J., 8, 787.

Burn, C. G., Hollander, A. G., and Crawford, J. H. (1943). Ibid., 26, 415 .

Carstens. M. (1950). Fortschr. Röntgenstr., 72, 339.

Corvisart, J. N. (1812). An Essay on the Organic Diseases and Lesions of the Heart and Great Vessels, from the Clinical Lectures of J. N. Corvisart. Edited by C. E. Ho:eau. Finley, Philadelphia. Quoted by Burn et al.

French, H. (1912). Trans. med. Soc. Lond., 35, 245.

Gore, I. (1947). Amer. Practit., Philad., 1, 292.

Gould, S. E. (1953). Pathology of the Heart, 1st ed., p. 820. Thomas, Springfield, Ill.

Higginson, J., and Keeley, K. J. (1951). Journal of Clinical Pathology 4, 342.

Hunter, W. C., and Benson, R. L. (1933). Amer. J. Path., 9. 593.

Joachim, H., and Mays, A. T. (1927). Amer. Heart J., 2, 682.

Jones, K. P., and Tilden, I. L. (1942). Hawaii med. J., 1, 295.

Millar, W. Ġ., and Ross, T. F. (1942). J. Path. Bact., 54, 455

Parkinson, J., Bedford, D. E., and Thomson, W. A. R. (1938) Quart. J. Med., 7, 455.

Sternberg. M. (1914). Das chronische partielle Herzaneurysma. Deutickè, Leipzig and Vienna.

Ungerleider, H. Ez and Gubner, R. (1945). In The Diagnosis and Treatment of Cardiovascuiar Disease, ed. Stroud, W. D., 3rd ed. Davis, Philadelphia, Vol. 1, p. 854.

Vivas-Salas, E. (1948). Amer. J. Dis. Child., 75, 92

Wilson, C. P. (1926). Amer. Heart J. ,1, 703, 